\title{
Fast and Real Life Object Detection System Using Simple Webcam
}

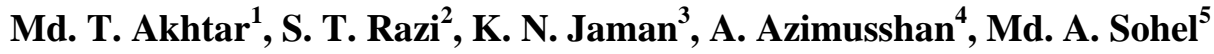 \\ ${ }^{1}$ Cyber Patrol Cell, Kolkata Police Directorate, Kolkata, India \\ ${ }^{2}$ IT, Logicoy Software Technology, Bangalore, India \\ ${ }^{3}$ Dept of CSE, Aliah University, Kolkata, Indian \\ ${ }^{4}$ Staffing \& Recruitment, Test Yantra Software Solutions, Bangalore, Indian \\ ${ }^{5}$ IT, Tata Consultancy Services, Kolkata, India
}

Available online at: www.isroset.org

Accepted: 20/Jun/2018, Online: 31/Aug/2018

\begin{abstract}
The project is designed to detect a real-life object using a simple webcam. The image captured by the webcam is to be enhanced and magnified and then is compared with similar type of image in our database to detect the type of image. The data being compared is binary string, a unique attribute is compared which has been acquired by feature extraction. The following technology can be used in face recognition system, defence system, production line or removal of defective product. We are using MATLAB to develop our project. The experiments conducted in accordance with proposed methods which are suitable for realtime surveillance system [1].
\end{abstract}

$\underline{\text { Keywords - Fast Object, Moving Object, Real-life Detection, Web Cam, MATLAB, Image Processing }}$

\section{INTRODUCTION}

This document will propose all features and procedures to develop the system. Our project will help computer to detect an object of different basic shapes on initial level. Next level will be to detect object having complex shape with the help of feature points. Further level will be to detect a particular object in an image having clustered objects or having group of objects. Detecting object in a streaming video.

The tests are taken to develop the project in the labs of Aliah University for the preparation of this paper. Section I contains the introduction; Section II contains the perspective, function of the product and characteristics of users; Section III contains minimum hardware and software requirements to carry out the project; section IV contains the schematic diagram and its module description; section $\mathrm{V}$ contains the architecture and essential data-flow-diagram and explain the methodology with class diagram and describes result with snapshots; Section VI tells about futuristic approaches and its limitation; Section VII concludes research work; Section VIII is our thanks and regards towards our mentor and supporters and Section IX contains the bibliography.

\section{SCOPE:}

- Fast and Real-Life Object Detection is designed for Govt. and Private Organization (like Airport, Malls, etc.) [2].

- The system handles all the operations and generates reports as soon as the test is finish.

\section{GENERAL DESCRIPTION}

2.1) PRODUCT PERSPECTIVE:

The system will be developed using the following technology:
1) MATLAB [3][4]

2) $C[5]$

2.2) PRODUCT FUNCTION:

1) Provide motion detection [6]

2) Provide Object detection

3) Provide Noise reduction [7]

\section{3) USER CHARACTERISTICS:}

a. Educational level: Users should be comfortable with the English language.

b. Experience: Users should have prior information about MATLAB and C.

c. Skills: Users should have basic knowledge and should be comfortable using general purpose applications on computer.

\section{4) ASSUMPTIONS}

1. The system will run on most known operating system (like 
$\mathrm{XP}$, windows 7, windows 8, windows server 2008, etc) platform where MATLAB is installed.

2. The processor must be at least $2 \mathrm{GHz}$ with $2 \mathrm{~GB}$ RAM and 1GB GPU.

3. The hardware for the client must be provided by the client.

\section{SYSTEM REQUIREMENTS SPECIFICATIONS}

\section{1) HARDWARE REQ:}

1. PC should be sufficiently fast with adequate memory of at least $2 \mathrm{GHz}$ with $2 \mathrm{~GB}$ RAM and $1 \mathrm{~GB}$ GP, 4 GB hard disk space is required to run this application.

2 . Screen resolution of at least $800 * 600$ required to properly view the screen.

\section{2) SOFTWARE REQ:}

1. Most windows operating system would work.

2. The MATLAB must be installed.

\section{MODULE DESCRIPTION}

\section{Schematic Diagram}

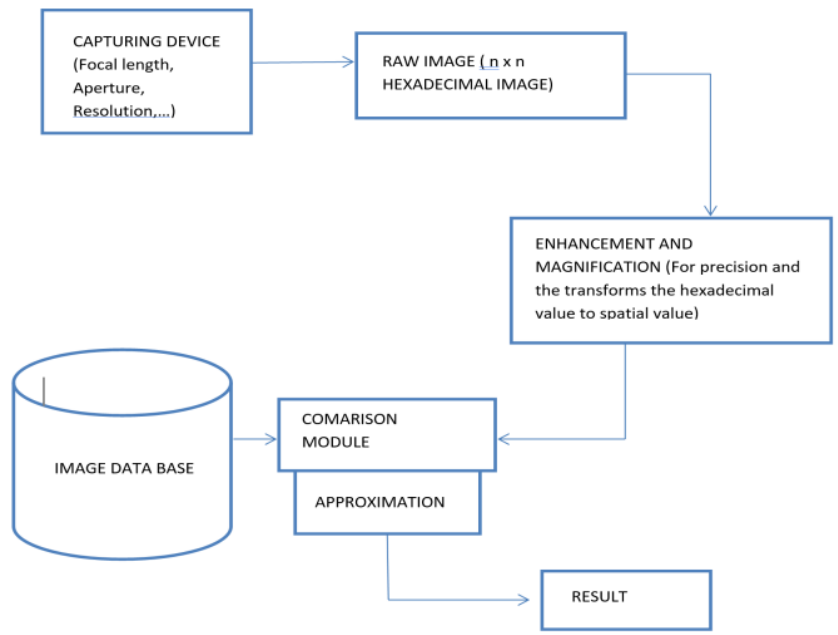

\section{1) WEBCAM MODULE}

It will capture raw images using the webcam and the hexadecimal data is stored into a matrix.

\section{2) ENHANCE RAW IMAGE MODULE}

This process requires us to use DCT (Discrete Cosine Transformation) to convert the hexadecimal value to spatial value and store it into a $8 \times 8$ or $4 \times 4$ matrix.

\section{3) FEATURE EXTRACTION MODULE}

In this module we simplify the amount of resource required to describe a large set of data accurately. This data of target Image is compared with the feature data already stored in our database.

\section{4) APPROXIMATION MODULE}

When trying to detect an object there can be percentage difference in features extracted from target data, and the features of Source data. This difference is normalized in this module.

\section{SYSTEM DESIGN}

\section{DATA FLOW DIAGRAM:}

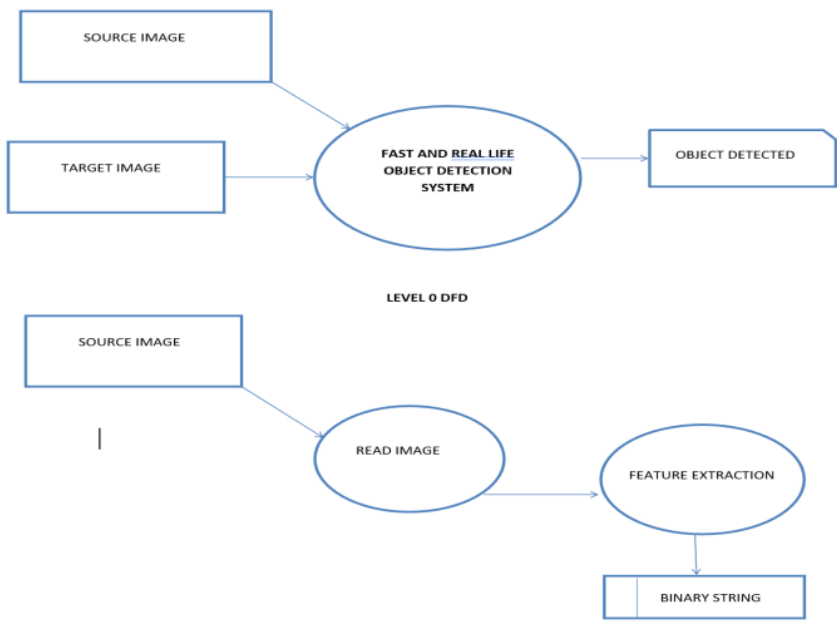

Figure 1. LEVEL 1 DFD (LEARNING PHASE)

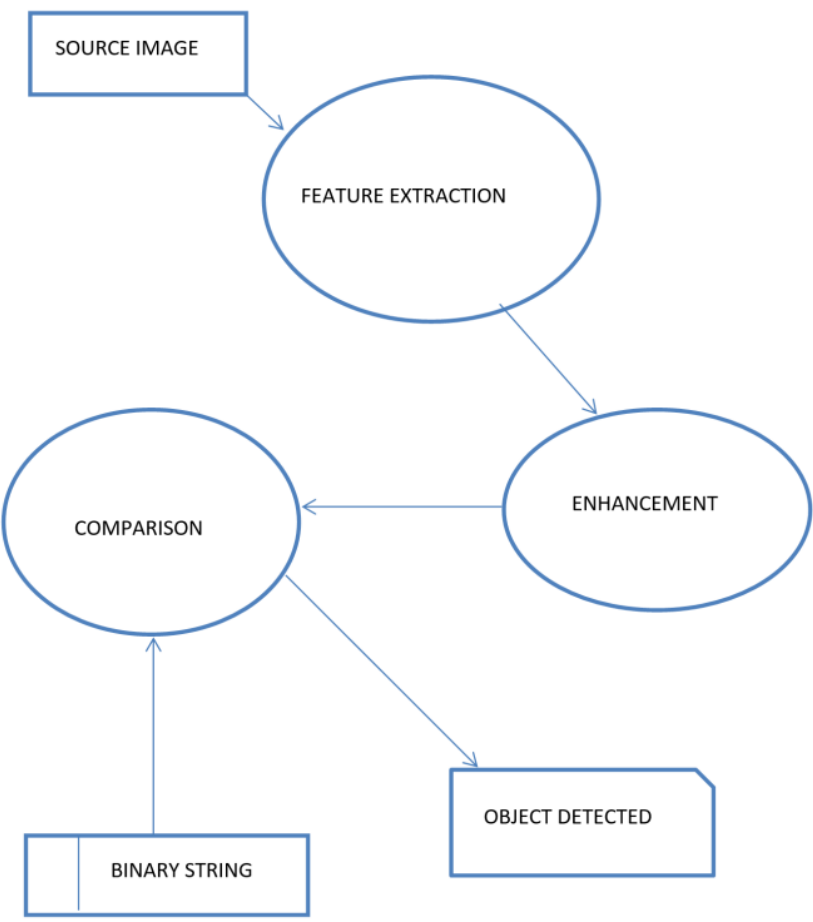

Figure 2. LEVEL 1 DFD (PREDICTING PHASE)

\section{CLASS DIAGRAM:}




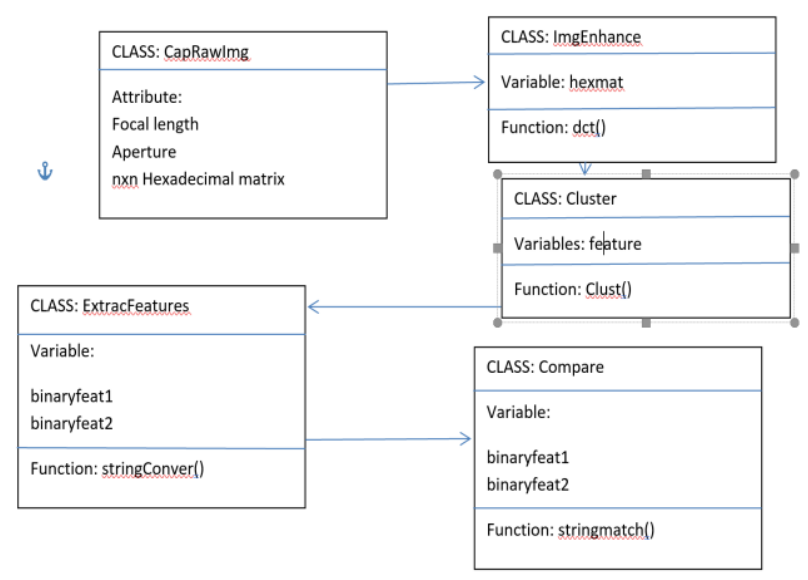

Figure 3. CLASS DIAGRAM

\section{SNAP SHOT:}
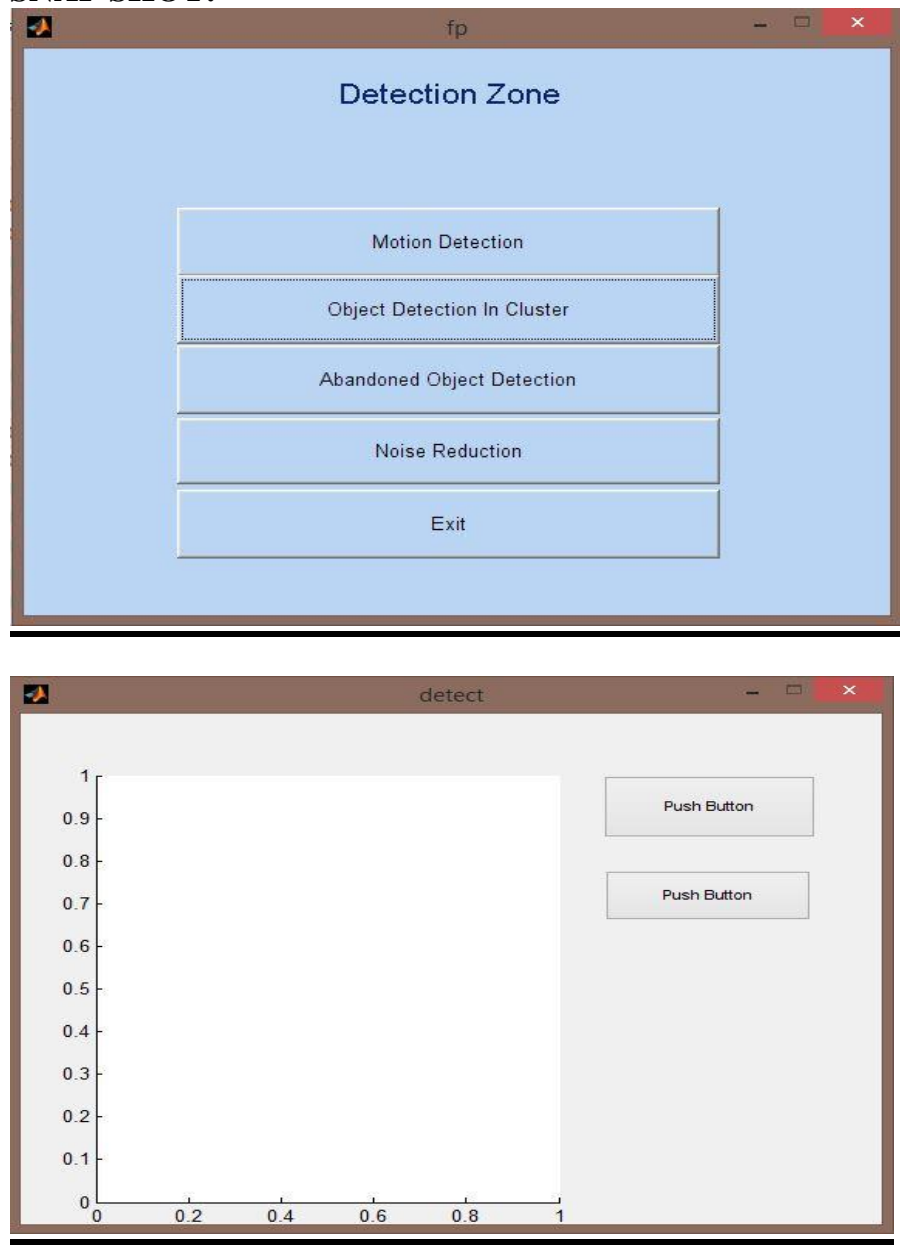

Detection trial 1 snap shots:
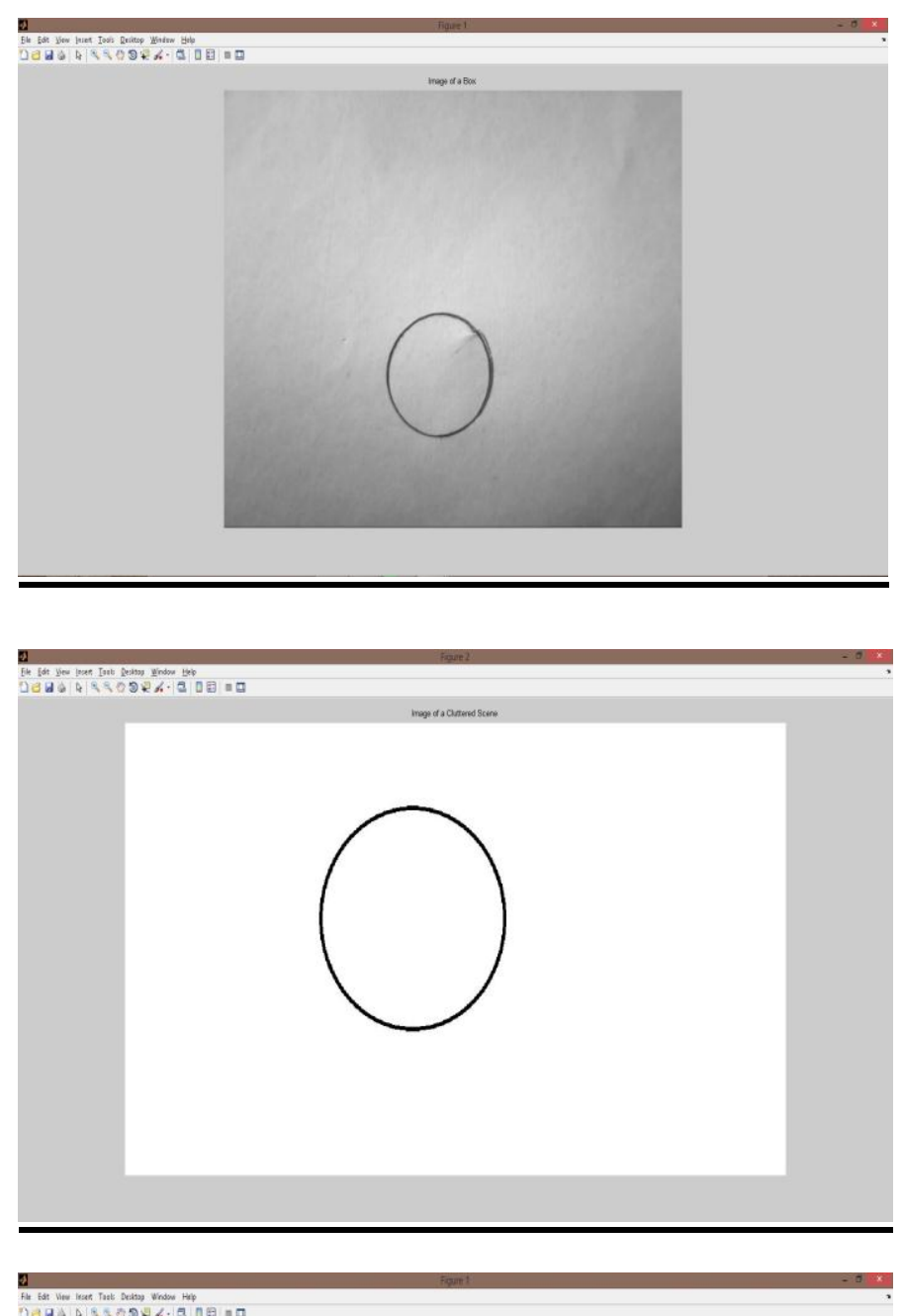

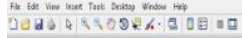

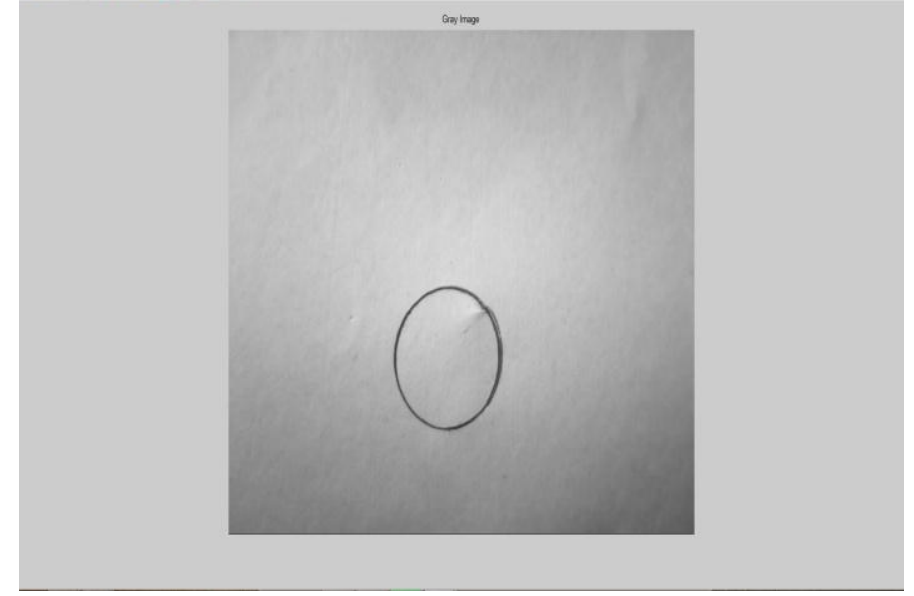



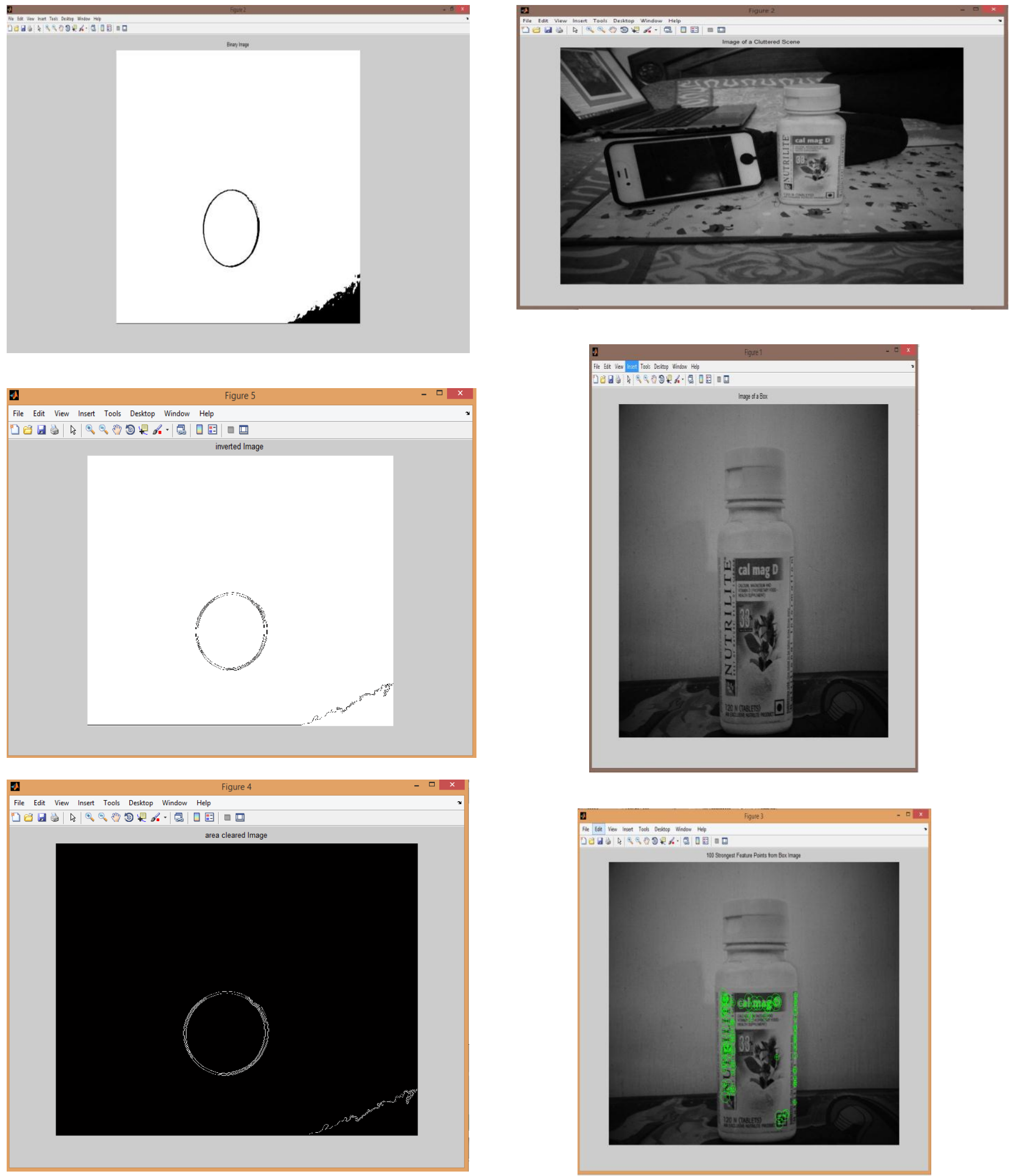

Detection trial 2 snap shots: 


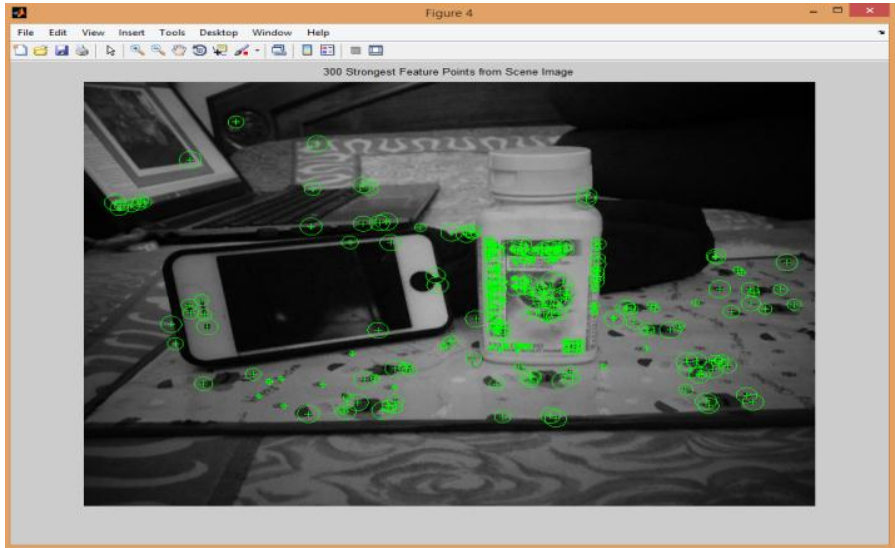

a

File Edit View Insert Tools Desktop Window Help

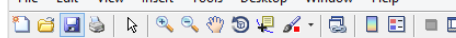

Clean Foreground
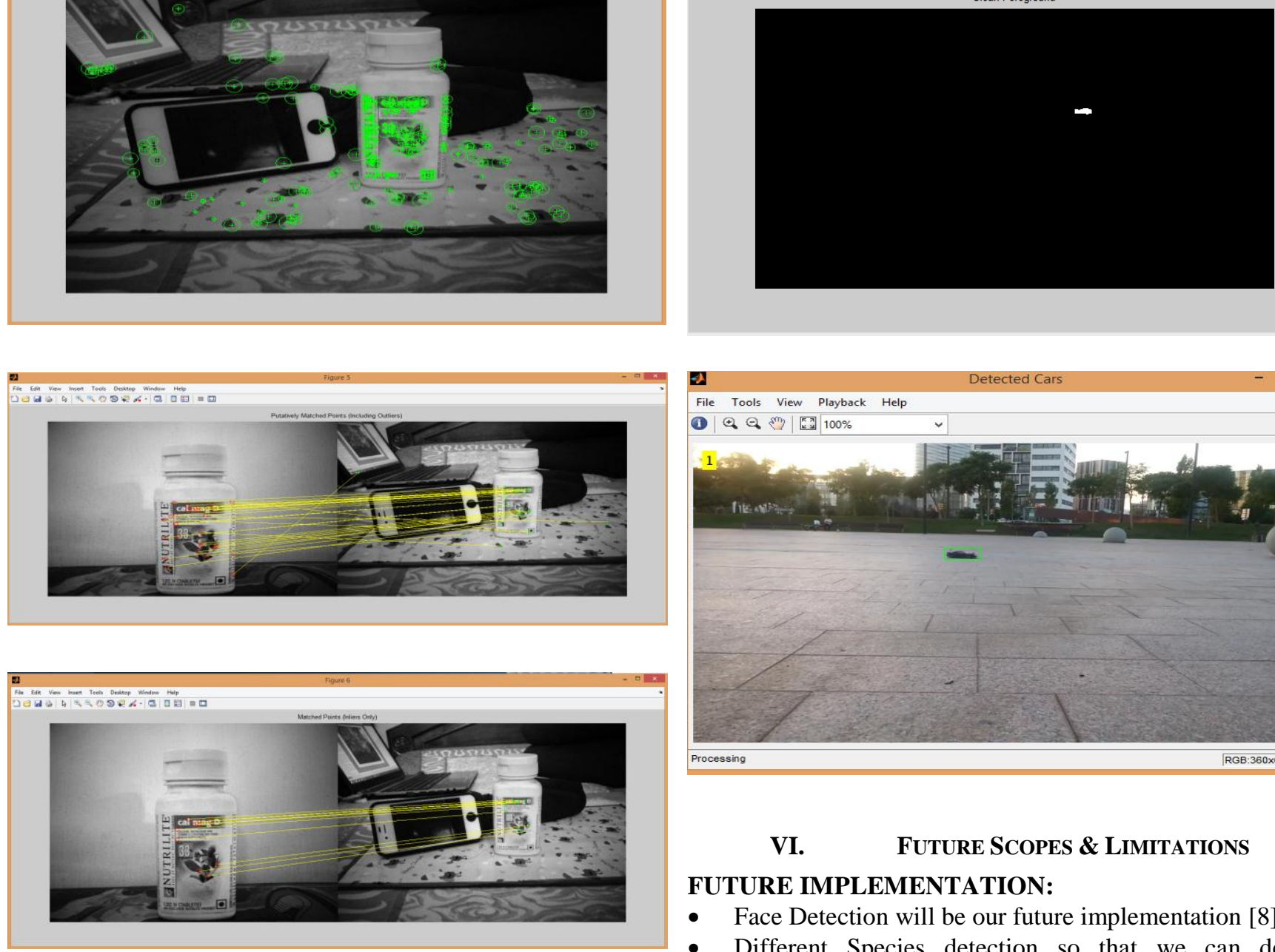

Detection trial 3 snap shots:

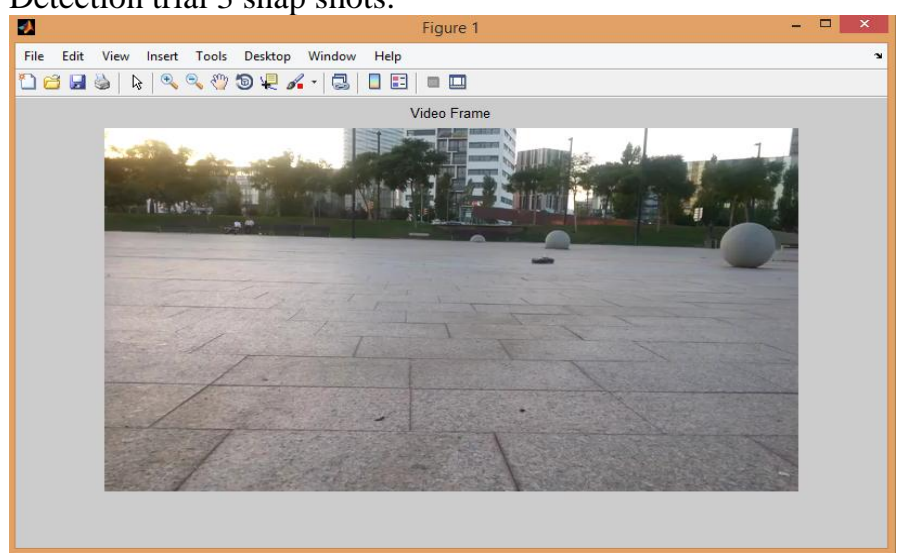

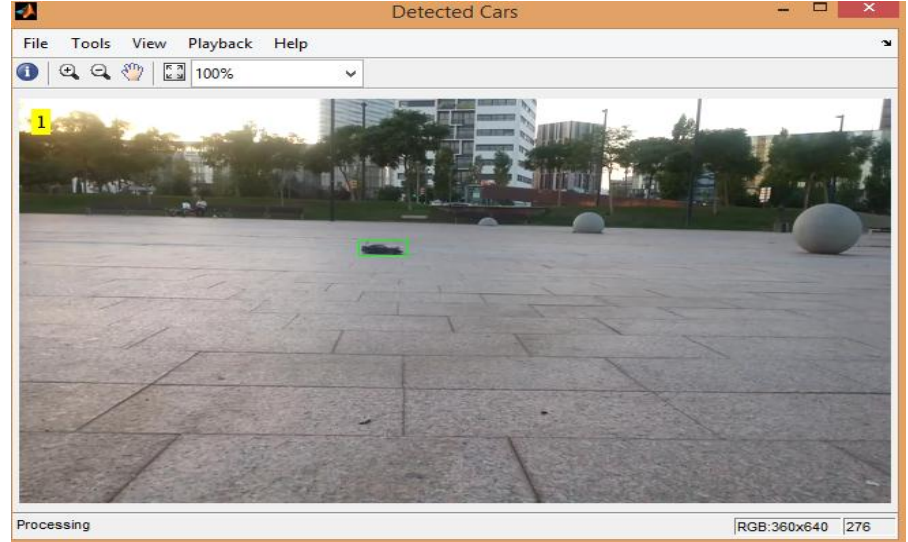

\section{FUTURE SCOPES \& LIMITATIONS}

FUTURE IMPLEMENTATION:

- Face Detection will be our future implementation [8].

- Different Species detection so that we can detect different species like human beings, dogs, elephants, fish.

- In production factories to check specific shape of the object.

- Car number plate detection and enhancing.

- Traffic density detection.

\section{CONCLUSION}

- We would like to conclude by saying that this particular project of ours is set to revolutionize the way the computer or any electronic device having camera percepts the real-life objects

- A step forward in computer vision and robotic vision.

Application of proper image processing and enhancing algorithm for efficient and fast object detection. 
VIII.

\section{ACKNOWLEDGEMENT}

We have taken effort in this project. However, it would not have been possible without the kind support and help of individuals. We would like to extend our sincere thanks to all of them. We are highly indebted to our mentor Mr. Golam Sarowar Hossain for his guidance and constant supervision as well as providing necessary information regarding the project and also for his support in completing the project.

We would like to thank our fellow team mates for their kind co-operation and encouragement to complete the project.

\section{REFERENCES}

[1]. Li Fang, School of Computer Science Nanyang Technological University, Singapore and Zhang Meng, Dunman High School Claire Chen Qian Hui River Valley High School, Singapore. "Smart Motion Detection Surveillance System". Published by IEEE on 21 July 2009.

[2]. Yash Gupta, Samriddhi Mishra, Deepti Sharma, "Smart Surveillance System", International Journal of Computer Sciences and Engineering, Vol.6, Issue.5, pp.780-784, 2018.

[3]. David Houcque, "Introduction to Matlab for Engineering Students", Northwestern University, 2005.

[4]. Matworks, "Getting Started with MATLAB", Matlb Primer.

[5]. Byron S Gottfried, "Schaum's Outline Of Programming With C", McGraw Hill Publication, 2010.

[6] Kala Chandrashekhar L, Manasa B S, "A Study on Segmentation of Moving Objects Under Dynamic Conditions", International Journal of Computer Sciences and Engineering, Vol.4, Issue.6, pp.173179, 2016.

[8]. Vikramsingh R. Parihar, Anagha P. Dhote, "A Novel Approach to Real Time Face Detection and Recognition", International Journal of Computer Sciences and Engineering, Vol.5, Issue.9, pp.62-67, 2017.

\section{Authors Profile}

Mr. Md. Tanjeem Akhtar pursed Bachelor of Technology from Aliah University, Kolkata in 2015 and Master of Technology from Aliah University in year 2017. He is currently working as Computer Analyst in Cyber Patrol Cell, Kolkata Police since 2017. His main research work focuses on Cryptography, Network Security, Data Mining \& Clustering

Techniques and IoT based education. He has not only good academic records but he is also a kasrismatic sports person who had represented his university in various games as captain and vice captain. His zeal in sports makes him more strategic and friendly in his working zone.

Miss. Suhana Tasneem Razi pursed Bachelor of Technology from Aliah University, Kolkata in year 2015. She is currently working as Trainee Engineer in Logicoy Technology Solutions. She works as an Java Developer in her team.
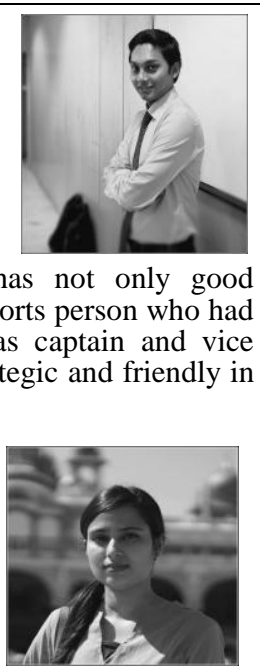

Mr. Kazi Nasim Zaman pursed Bachelor of Technology from Aliah University, Kolkata in 2015. He has submerged himself in his research work.

Mr. Abu Azimusshan pursed Bachelor of Technology from Aliah University, Kolkata in year 2015. He is currently working as an UK/EUROPE IT recruiter in Test Yantra Software Solutions. He is professional in the field. Recently he has been proclaimed as a Global \#Humanizer awarded by Momtaz Alsolh, Founder of Global \#Humanizer for supporting campaign called "Bread without Butter which concerns the need to respect human rights and to abide by the Labor Law without fail.

Mr. Md. Amir Sohel pursed Bachelor of Technology from Aliah University, Kolkata in 2015. He is currently working as Developer in Tata Consultancy Services, Kolkata. His main research work focuses on Java and Advanced Java. He loves outing and photography.
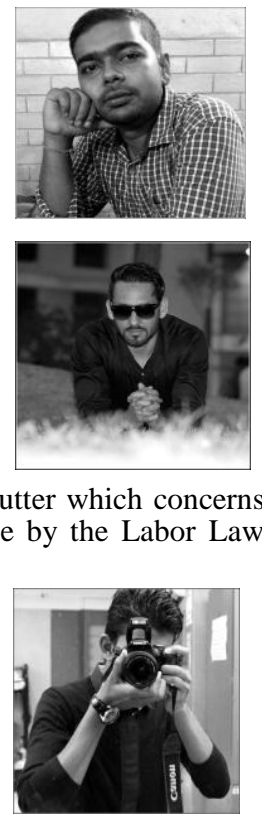